\title{
Correction to: LightCpG: a multi-view CpG sites detection on single-cell whole genome sequence data
}

Limin Jiang ${ }^{1}$, Chongqing Wang ${ }^{2}$, Jijun Tang ${ }^{1,3}$ and Fei Guo ${ }^{1 *}$ (D)

\section{Correction to: BMC Genomics \\ https://doi.org/10.1186/s12864-019-5654-9}

Following the publication of this article [1], the authors reported that the images of Fig. 2 and Fig. 3 were switched during typesetting. The correct Fig. 2 and Fig. 3 are reproduced in this Correction article. The original article has also been corrected.

\section{Author details}

'School of Computer Science and Technology, College of Intelligence and Computing, Tianjin University, Tianjin, China. ${ }^{2}$ School of Chemical Engineering and Technology, Tianjin University, Tianjin, China. ${ }^{3}$ Department of Computer Science and Engineering, University of South Carolina, Columbia, SC, USA.

Received: 29 April 2019 Accepted: 29 April 2019

Published online: 13 May 2019

\section{Reference}

1. Jiang, et al. LightCpG: a multi-view CpG sites detection on single-cell whole genome sequence data. BMC Genomics. 2019;20:306 https://doi.org/10. 1186/s12864-019-5654-9.

\footnotetext{
* Correspondence: guofeieileen@163.com

${ }^{1}$ School of Computer Science and Technology, College of Intelligence and Computing, Tianjin University, Tianjin, China

Full list of author information is available at the end of the article
} 


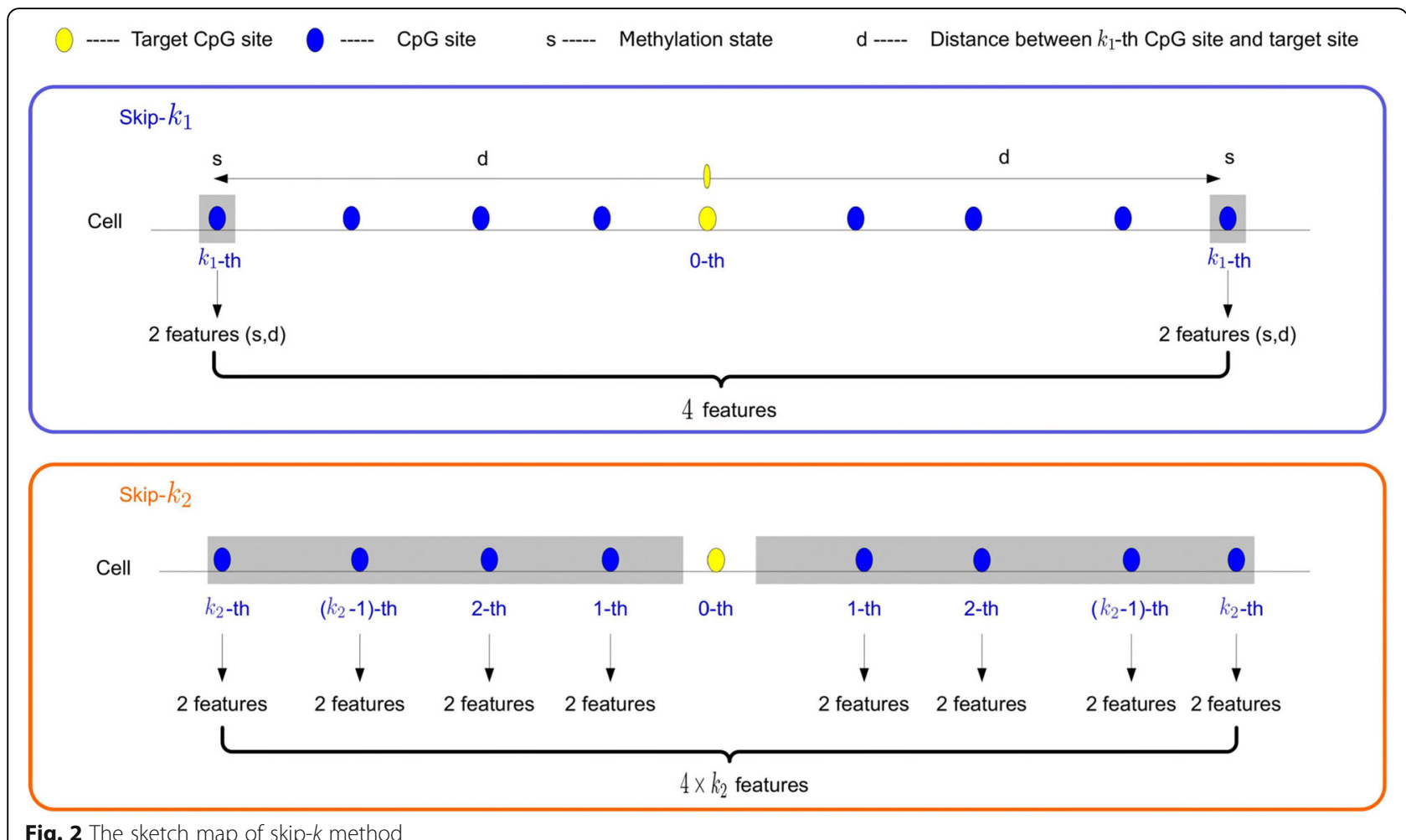

Fig. 2 The sketch map of skip- $k$ method

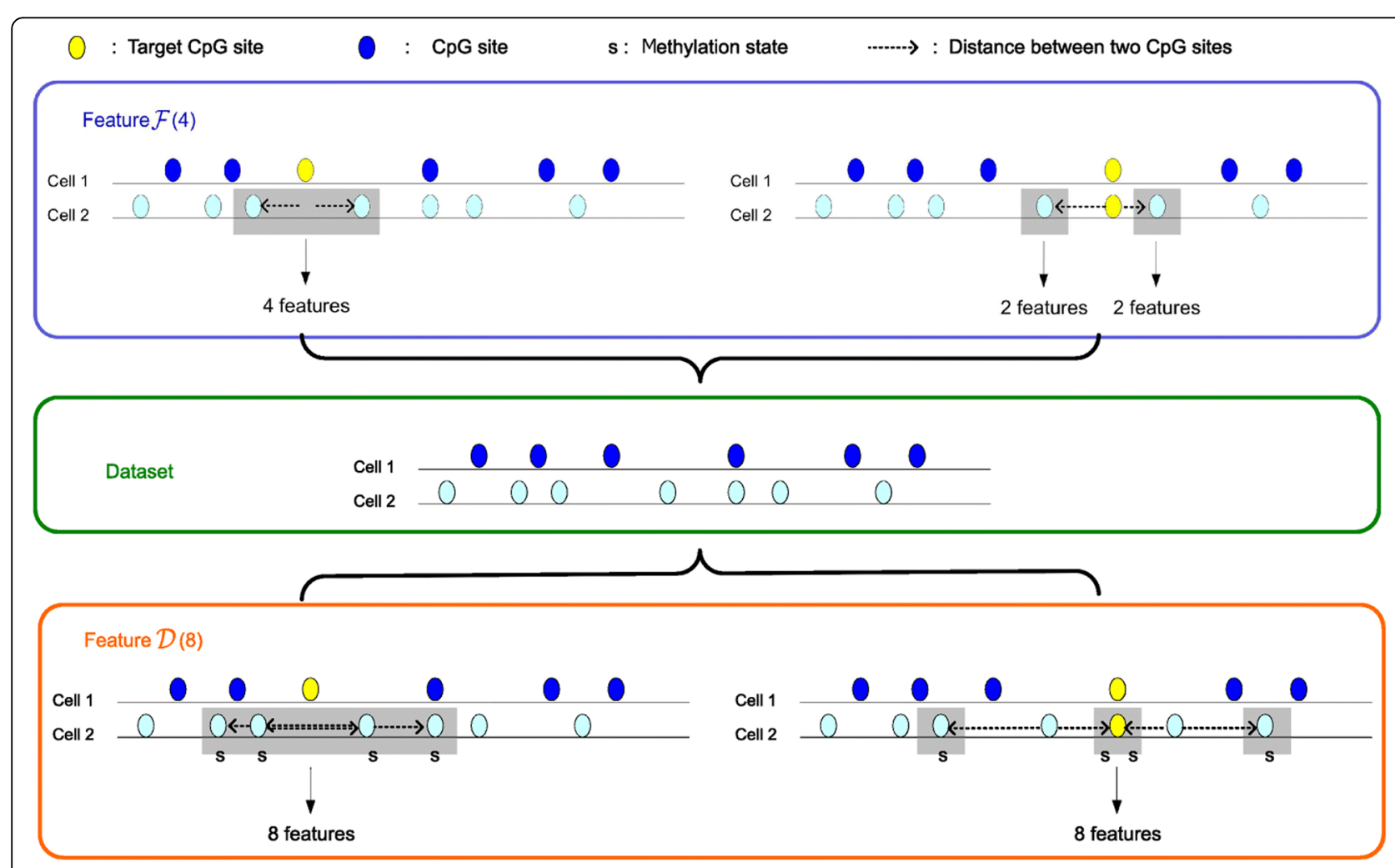

Fig. 3 The sketch map of feature $\mathcal{F}$ and feature $\mathcal{D}$ 